\title{
Design and Application on the Composite Rail of Column-Beams in Gantry Machine
}

\author{
Hua Lu ${ }^{1, a^{*}}$ Dewei Tang ${ }^{2}$ \\ ${ }^{1}$ Changzhou Institute Of Mechatronic Technology, Changzhou, Jiangsu, China \\ ${ }^{2}$ Changzhou Changlong Machine Tool Manufacturing Co.,Ltd. \\ aemail:913102391@qq.com
}

Keywords: moving beams CNC gantry machine. column beams composite rail. Column. beams.

Abstract. Column - crossbar rail is the heart of the Moving beams CNC gantry machine which is now widely used in Machinery manufacturing. Whether the structure is rational directly affects the dynamic performance of the whole machine and machining accuracy. The traditional slide, linear rolling and hydrostatic guideway all have their own drawbacks. In order to improve the existing condition, we designed a brand new column beams compound rail. This new structure provides a wider rail, larger carrying capacity, higher rigidity and can also adjust the gap, which has greatly improved rigidity and dynamic response speed of the machine, thus has improved the entire machining accuracy. The application of this structure has successfully lead Gantry CNC machine tools into the crux of the national key industries.

\section{Introduction}

A large number of important industries in China, such as power-generation equipment (water electricity, wind electricity, nuclear electricity), aeronautics, astronautics, shipping and automobile industry, are in need of high-precise and CNC gantry machines with big moving beams, which serve as a pressing demand for modern equipment manufacturing. With the rapid economic development in our country, the government is paying a growing attention to the development of industries related to heavy CNC gantry milling machines. Currently, CNC gantry machines have been widely applied to machine building industry, and the rail that moves up and down - column rail, is considered the most essential component of gantry machine. The rail is a sliding pair made up of two relatively motional joining surfaces, and is composed of supporting component and executive component; it is the heart of a machine, as well as one of the most vital part, it can determine the rigidity, preciseness and maintenance of preciseness to a large degree. It is one of the most significant factors that assure the processing accuracy of a machine.

There are basically three types of rails that are mostly used in modern CNC machines: sliding rail, rolling rail and hydrostatic rail.

1. Sliding rail consists of rectangle sliding rail and round sliding rail. Rectangle rail is advantageous in single structure and convenient production, testing and maintenance, wide guiding surface, high bearing capacity and rigidity, so it is extensively used; but rail gaps need to be adjusted by pressing plate or panels, even readjustment once abraded, with a low contact rigidity. In order to assure normal operation, a proper gap should be kept between rail surfaces: smaller gap would increase frictional resistance, while bigger gap declines guiding accuracy. The gaps are ensured by scraping, which would take a sum of labor; besides, after used for a long time, rails may widen the gaps for abrasion; round rail is easy to produce, and an accurate cooperation can be achieved by external grinding and internal lapping, but the gaps cannot be adjusted once abraded; 
for avoiding rotating, a spline or plane can be made on the surface, but it cannot bear too much torque and is only available in axial load.

2. Linear rolling guide is featured with low frictional resistance, flexible movement, low abrasion, long-time accuracy, and small difference in static friction coefficient, and "creeping" phenomenon would not easily occur at lower speed, thus it is moving steadily. But rolling rail is defected in the point-contact or line-contact of rail surface and rolling body, low resistance to shock, and big contact stress; consequently, it requires highly on rail surface rigidity, shape accuracy and the dimensional accuracy of rolling body.

3. The outstanding points in hydrostatic rail lie in the low impact of moving speed and loading changes on oil film thickness, with a liquid friction coefficient of about only 0.005 and a strong vibration resistance. However, it has a relatively complicated internal structure and demands an additional oil supply system and highly-cleaned lubricating oil, which is of great cost and difficult maintenance[1].

Aiming at the defects mentioned above, namely, low accuracy and big gap in rectangle sliding rails, incapability of bearing big torque for round sliding rails, weak seismic resistance of rolling rails, and big contact stress and high cost for hydrostatic rails, the paper has designed a composite rail of column-beams in gantry machine that is of wide rail surface, big bearing capacity, high rigidity and an adjustable gap.

\section{Design Plan}

Introduction of Gantry Machine. The entire machine is made up of body, working table, columns, moving beam, sliding saddle, sliding ram, together with driving system, dragging system, hydraulic system, cooling system and pneumatic system. As is shown in Figure 1. The new CNC gantry machine adopts a moving-beam elevation type, and a layout of double-column and body fixed connecting on both sides. The $\mathrm{X}$ axis refers to the forward-backward movement by working table along the machine body, while $\mathrm{Y}$ axis refers to the left-right movement by sliding ram along the beam; and the up-down movement of sliding ram is called $\mathrm{Z}$ axis while the up-down movement of moving beam along the column $\mathrm{W}$ axis[2]. The $\mathrm{W}$ axis forms the composite rail of column-beam, which is comprised of beam, left and right column on each side of the beam; there is a lead screw on each of the column: the left column cooperates with the beam by left rail equipment, while the right column works with the beam by right rail equipment.
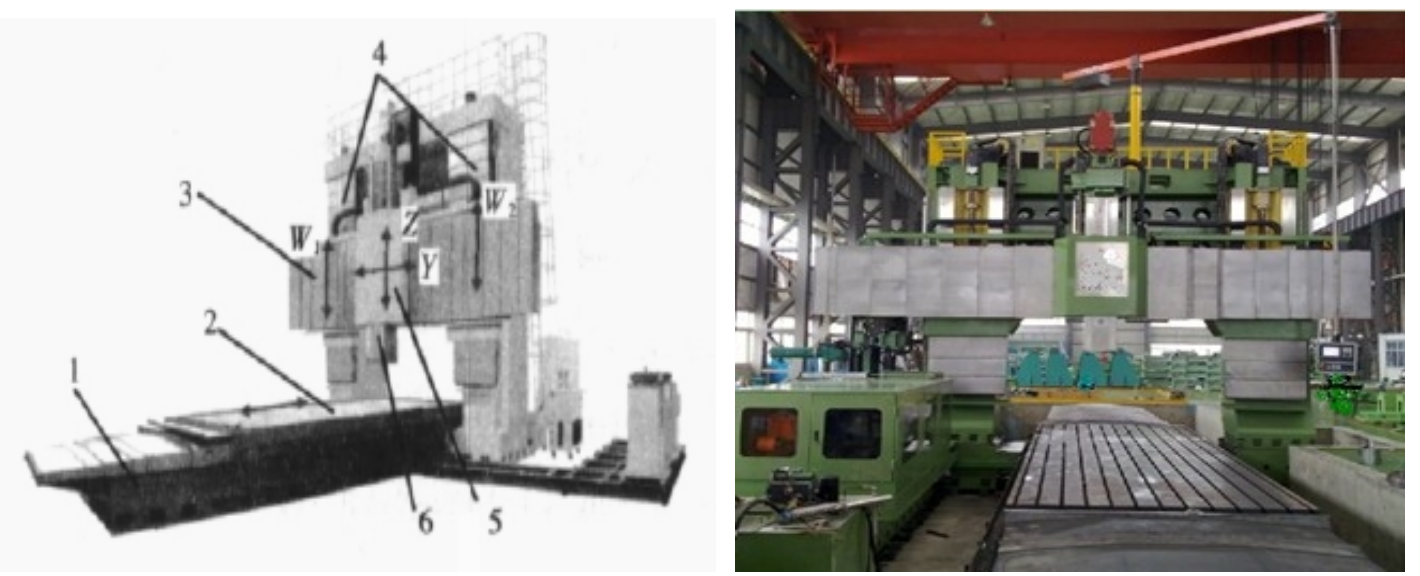

Figure 1. Outlook of Gantry machine

1-Body 2-Working table 3-Moving beam 4-Double-column 5-Sliding saddle 6- Sliding ram 
Detailed Structural Design of Composite Rail of Column-Beams. As is shown in Figure 2.
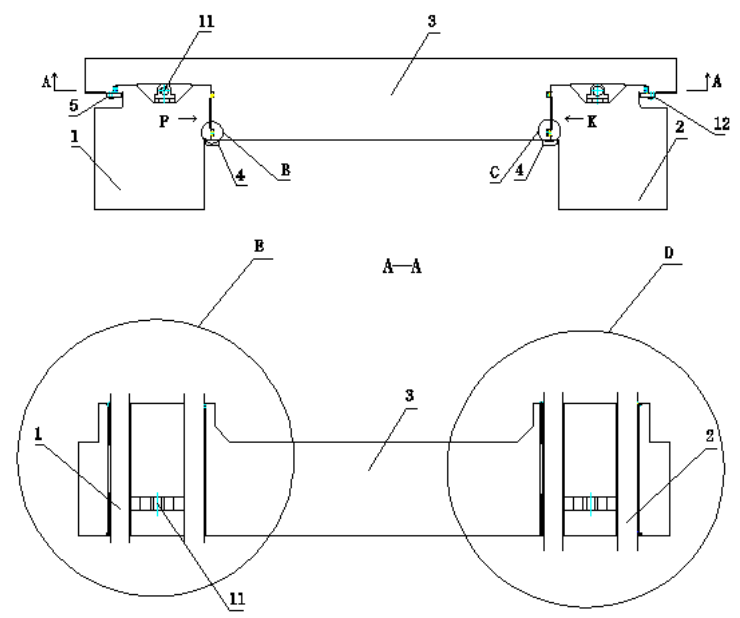

B

$\mathrm{C}$
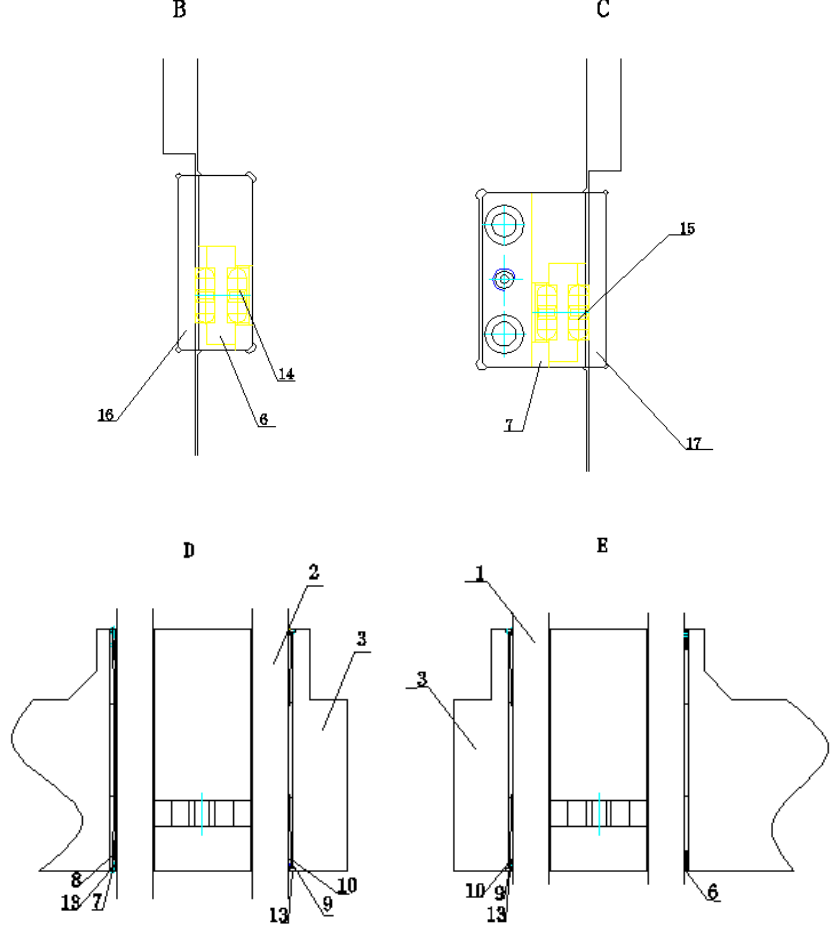

$\mathrm{K}$

$\mathrm{P}$
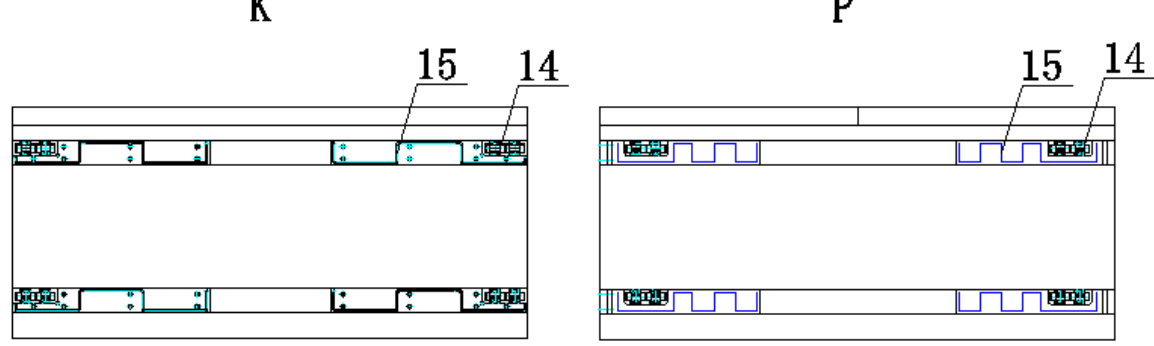

Figure 2. Structure of Composite Rail of Column-Beams

1-Left column 2-Right column 3-Beam 4-Internal pressing plate 5-Left external pressing plate 6-Criterion-orientation module 7-Adjustable internal panel module 8-Internal panel module 9-External panel module 10-External panel baseplate 11-Lead screw 12-Right external pressing plate 13-Dead plate 14-Sliding needle bearing 15-Plastic belt 16-Left guiding rail 17-Right guiding rail 
The composite rail of column-beams in gantry machine is shown in Figure 2. The left column 1 and right column 2 are respectively set at each side of beam 3. Both columns 1 and 2 are equipped with a lead screw 11, and left column 1 sliding fits beam 3 by left guiding rail while right column 2 sliding fits beam 3 by right guiding rail. There are internal pressing plates 4 fixed between left column 1 and beam 3, as well as right column 2 and beam 3. A criterion guiding-rail device is set on the left rail and the device is made up of four criterion-orientation devices and left guiding rail 16, which cooperate with one another. The criterion-orientation device is fixed at one side of beam 3 , with left guiding rail fixed beside left column 1; the criterion-orientation device refers to beam criterion-orientation module 6 , which is embedded in beam 3 with sliding wear-resisting devices installed at both sides and sliding fixes with left rail 16. The right rail is equipped with a device that can adjust rails, which is composed of four adjustable devices and right guiding rail 17; the adjustable device sliding fixes with right guiding rail 17 and is fixed at the other side of beam 3 . Right guiding rail 17 is set beside the right column, and the adjustable device is made up of adjustable internal panel module 7 and internal panel module 8 that 7 is set upon, which, is embedded in beam 3. On both sides of adjustable internal panel module 7, sliding wear-resisting devices are installed, which is formed by sliding needle bearing 14 and plastic belt 15 . The adjustable internal panel module 7 sliding fixes with right rail 17 and is equipped with dead plates 13 on both ends, which is fixed upon beam 3. Two sets of sliding panels are also set respectively on left and right rail devices: left sliding panels are fixed on beam 3 to fix with left column 1, while right sliding panels are fixed on beam 3 to fix with right column 2 . The sliding panels are all constituted by external panel module 9 and external panel baseplate 10 which 9 is set upon; left sliding panels and right sliding panels are both fixed on beam 3 by dead plate 13. Plastic belt 15 is set on the composite device of left column 1, right column 2 and beam 3 by glue; 15 is a PTFE plastic belt, which is cohered on internal pressing plate 4, external pressing plate 5 and right external pressing plate 12. A coping pressing plate is fixed on the joint surface or sliding surface to assure the gaps between beam and column joint surface. The left and right guiding rails are formed by hardened steel rails.

Adjust the gap between adjustable internal panel module 7 on beam 3 and right guiding rail 17, assure the gap between criterion-orientation module 6 on beam 3 and the left guiding rail 16 of column 1, and make the two gaps zero, use a screw to fix dead plate 13 on the upper and lower surfaces of the beam. Then, adjust the gap of left sliding panel between column 1 and beam 3 and the right sliding panel between column 2 and beam 3, and then again fix dead plate 13 on the upper and lower surfaces of beam 3 with the help of a screw.

Slide the needle bearing 14 is a standard component, installation and lubrication is simple, the advantages of easy protection and adjustment[3]. The structure shown in Figure 3. Since the needle-rolling in a closed raceway, it can be used on a large travel rail. 


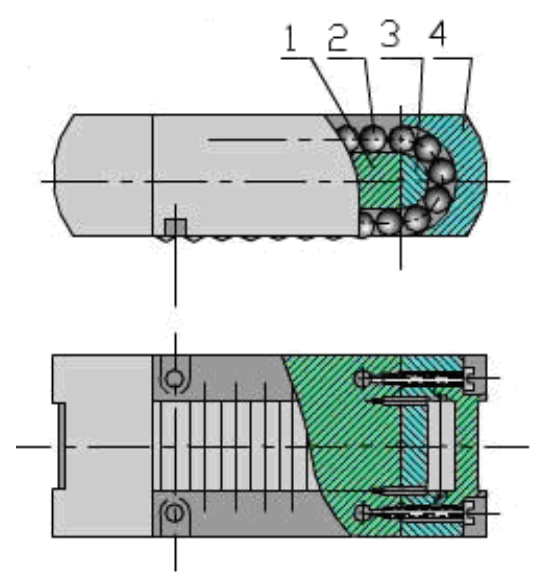

Figure 3. Sliding needle roller bearings

1-Body 2-Needle 3-Guide piece 4-Reflector

\section{Checking rail structure size}

Rail work in the environment of large temperature variations, it should be guide clearance checked after being identified in precision and fit. In order not to be caught in working, rail minimum clearance should be greater than or equal to zero, namely $\Delta \min \geq 0$

1. Rail minimum clearance with the following formula:

$$
\Delta \min =\operatorname{Dmin}\left[1+\alpha_{\mathrm{k}}(\mathrm{t}-\mathrm{t} 0)\right]-\mathrm{dmax}\left[1+\alpha_{\mathrm{Z}}(\mathrm{t}-\mathrm{t} 0)\right](\mathrm{mm})
$$

Where: t-Operating temperature $\left({ }^{\circ} \mathrm{C}\right)$

t 0 -Manufacture temperature $\left({ }^{\circ} \mathrm{C}\right)$

Dmin-Inclusive parts minimum size at the $\mathrm{t} 0(\mathrm{~mm})$

dmax-The contained parts maximum size at the t0 (mm)

$\alpha \mathrm{k}$-Linear expansion coefficient of the inclusive parts material $\left(1 /{ }^{\circ} \mathrm{C}\right)$

$\alpha_{\mathrm{Z}}$-Linear expansion coefficient of the contained parts material $\left(1 /{ }^{\circ} \mathrm{C}\right)$

To ensure the accuracy of the guide, the rail largest gap should be less than or equal to the allowable value, namely $\Delta \max \leq[\Delta \max ]$

2. Rail largest clearance with the following formula:

$$
\Delta \max =\operatorname{Dmax}\left[1+\alpha_{\mathrm{k}}(\mathrm{t}-\mathrm{t} 0)\right]-\mathrm{dmin}\left[1+\alpha_{\mathrm{Z}}(\mathrm{t}-\mathrm{t} \quad 0)\right](\mathrm{mm})
$$

Where: Dmax-The inclusive parts maximum size at the $\mathrm{t} 0(\mathrm{~mm})$ dmin-The contained parts minimum size at the $\mathrm{t} 0(\mathrm{~mm})$

\section{Features of the Composite Rail of Column-Beams}

To apply the composite rail of column-beams in gantry machines designed above can ensure a wider guide-way, bigger bearing capacity and higher rigidity. A criterion-orientation device is set between left column and beam, while an adjustable device is set between right column and beam, and the device can adjust the gap between columns and the beam in time and guarantee accuracy during practical use. Sliding needle bearings are installed on the criterion-orientation device and adjustable device that change the original sliding friction to the combination of sliding and rolling friction that reduces friction and assures the long-term stability of rail accuracy and processing 
accuracy. PTFE plastic belts are set on the contact surface of columns and the beam in order to lessen the difference between dynamic and static friction coefficient; the "creeping" phenomenon would not easily occur at lower speed, and machines can move steadily, reduce power loss of the electric machine and increase processing ability. The left and right guiding rails are both made from hardened steel, whose abrasive resistance is 5-10 times higher than normal gray iron: the enhanced abrasive resistance can help keep orientation accuracy for a longer time and extend service life. The advantages in adopting the design rest with increasing the accuracy and bearing capacity of guiding rails, reducing losses, extending service life and lowering producing cost.

\section{Conclusion}

According to experts' appraisal, the composite rail of column-beams in gantry machine enjoys a wider guide-way and bigger bearing capacity, higher rigidity, less difference in dynamic and static friction coefficient, and the "creeping" phenomenon would not easily occur at lower speed; it can move steadily and change the original sliding friction to the combination of sliding and rolling friction that reduces friction and assures the long-term stability of rail accuracy and processing accuracy, greatly declines the power loss of electric machine and increase processing ability. The abrasive resistance of hardened steel rail is 5-10 times higher than common gray iron: the enhanced abrasive resistance can help keep orientation accuracy for a longer time and extend service life.

At present, gantry machines that adopt the composite structure have been put to use: the machines are fast in dynamic respond with no creeping and can assure the machine performance. Because the dynamic performance of the entire machine has been enormously improved, the component processing accuracy has also been raised, which is just the essence of successfully applying the CNC gantry machines of such structure to key national industries.

\section{Acknowledgements}

Project supported by the Plans of the Senior Visit Engineer of vocational colleges of Jiangsu province (Grant No. 2014FG006)

\section{References}

[1] BI Cheng-en,DING Nai-jian, Modern CNC machine tools[M], Beijing,Mechanical Industry Press, 1993

[2] ZHANG Li-li,WU Chun-yu,WANG He,WANG Hai-ying.The development and application of new type $\mathrm{CNC}$ maching tool with moving crossrail with three guideways [J],Machinery Design\&Manufacture, 2008(5):98-99

[3] J.Matsumoto. Numerical Analysis Technology on NSK Linear Guides for Machine Tools. NSK Technical Journal No.676(2003):33-41 